\title{
Partial Reduplication in Some Austronesian Formosan Languages
}

\author{
SHIH-CHI STELLA YEH \\ National Tsing Hua University
}

\section{Introduction}

Reduplicative infixation has been a hotly debated topic, especially the invariant shape and the position of reduplicants. In the Amis language and several Austronesian Formosan languages, the pattern of partial reduplication seems to be infixation - copying a bimoraic form from the right edge except the final consonant. The main concern of this paper will be to evaluate the functions of Alignment constraints in terms of the position and the size of reduplicants, utilizing Optimality Theory. Languages mentioned in this paper display a more complete typology for the mora alignment constraint (Chrowhurst 2004) where the evaluation applies on the mora tier. In addition, while the invariant shape of the reduplicant can be predicted through alignment interactions in several languages (Gafos 1998, Hendrick 2001, Chrowhurst 2004), Amis and Thao differ. A constraint referring to the size is still necessary. I propose that the reduplicant position can be accounted for by Alignment, but the invariant shape should appeal to the Generalized Template constraint Red=Stem in Amis and Thao.

The organization of this paper is as follows. The first section presents the reduplicative patterns in Formosan languages Amis, Pazih, Paiwan and Thao. Section two displays the functions of Alignment constraints and illustrates an analysis regarding the positions of reduplicants. Section three is concerned with the templatic use in reduplication. I argue that the templatic constraint may not be substituted with Alignment interactions. The final section concludes the paper and discusses implications.

\section{Description of suffixal reduplicative patterns}

Suffixal reduplication in Amis and in several relevant Formosan languages is presented here. Amis is spoken by aboriginal people in the eastern territories of Taiwan. Based on my fieldnotes, one of the Amis reduplicative patterns, suffixal reduplication, copies material of bimoraic size from the right edge minus the rootfinal segment, which is always a consonant in content words, as in (1). This language permits onset clusters in word-initial position, and a maximum of one coda consonant. Therefore a tri-consonantal sequence word-medially is not 
possible. ('-' stands for reduplicant morpheme boundaries; '=' represents general morpheme boundaries.)

(1) Suffixal reduplication in Amis

\begin{tabular}{|c|c|c|}
\hline 1. ma.má? & ma.ma.-ma.má-? & 'father sg./pl.' \\
\hline lu.pás & lu.pa.-lu.pa.-s=án & 'peach/woodlands of peaches' \\
\hline ru.nî? & ru.ni.-ru.ni-..?=án & 'gourd/field of gourds' \\
\hline ma=li.náł & misa=li.ya.-li.ná-ł & 'work/pretend working' \\
\hline a.lu.pál & a.lu.pa.-1u.pa.-1=án & 'persimmon/woodlands of persimmons' \\
\hline ka.ła.fú? & ka.ła.fu.-ła.fú-? & 'child-in-law sg./pl.' \\
\hline ta.ka.ráw & ta.ka.ra.-ka.rá-w & 'tall/every subject is tall' \\
\hline patsî́ón & kara=patsilə-tsilá-y & 'big parotid bone sg./having big parotids' \\
\hline tam.łáw & tam.ła-m.łá-w & 'person sg./pl.' \\
\hline fay.tsál & fay.tsa-n.tsá-1 & 'good/every subject is good' \\
\hline sin.sî́? & sin.si-n.sí-? & 'teacher sg./pl.' \\
\hline mi=nəynón & 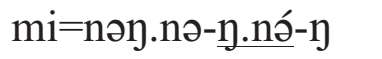 & 'look/every subject is looking' \\
\hline kih.pits & kih.pi-h.pí-ts & 'thin/every subject is thin' \\
\hline
\end{tabular}

The reduplicant mirrors two syllables from the right edge minus root-final consonant in (a) and (b). For words containing medial consonant clusters in (c), the reduplicants copy the last syllable plus the preceding coda minus root-final consonant. Assuming that codas are moraic except word-final ones, the reduplicants mirror two morae from the right edge except final consonants.

Formosan languages Thao, Paiwan, and Pazih resemble Amis suffixal reduplication in copying two morae from the right side minus the final consonant. In (2), the Pazih reduplicant is of the shape CVCV; the copy skips over the final consonant if there is one. Pazih permits Nasal-Consonant medial clusters in accord with the place feature, but they are not found in the reduplicative pattern.

(2) Pazih reduplication (Li and Tsuchida 2001)

$\begin{array}{lll}\text { ma=baza } & \mathrm{m}=\text { in=a=baza-baza } & \text { 'to know/very knowledgeable' } \\ \text { ta=niti } & \text { ta=niti-niti } & \text { 'angry/very angry' } \\ \text { zizaj } & \mathrm{mu}=\text { ziza-ziza-j } & \text { 'old/very old' } \\ \text { baket } & \mathrm{maa}=\text { bake-bake-t } & \text { 'to hit/to hit each other' }\end{array}$

A northern dialect of the Paiwan language displays similar patterns, as shown in (3). Like Pazih, word-internal codas are rare so that medial clusters are uncommon. The reduplicants copy two syllables from the right edge except rootfinal consonants. 
(3) Paiwan reduplication (Chang 2000, Tseng 2002)

\begin{tabular}{|c|c|c|}
\hline ivu & ivu-ivu & 'to talk/talking' \\
\hline lava & $\mathrm{k}=\mathrm{em}=$ alava-lava & 'to wait/waiting' \\
\hline & alemeqe-meqe-m & 'sweet/sweety' \\
\hline $\operatorname{lid}^{\mathrm{j}} \mathrm{ikid}^{\mathrm{j}}$ & $\mathrm{kad}^{\mathrm{j}} \mathrm{iki}-\mathrm{d}^{\mathrm{j}} \mathrm{iki}-\mathrm{d}^{\mathrm{j}}$ & 'to flash/flashing' \\
\hline
\end{tabular}

In the more complex case in (4), Thao suffixal reduplication copies the last two syllables minus word-final consonant in $(\mathrm{C}) \mathrm{CVCV}(\mathrm{C})$ words. For words with medial consonant clusters $\left.\left(\left[{ }_{\sigma} \mathrm{CC}, \mathrm{C}_{\sigma}\right]\left[_{\sigma} \mathrm{C} \text { or } \mathrm{C}_{\sigma}\right]\right]_{\sigma} \mathrm{CC}\right)$, the reduplicants mirror the final vowel and the two consonants preceding it, skipping over final-consonants.

(4) Thao reduplication (Chang 1998, Blust 2003)
a. šna.ra
$\mathrm{pa}=\check{\text { snara }}$-nara
'to ignite/to burn s.t. repeatedly'
qu.li.ǔ̌
mia $=$ quliu-liu-š
'long/stretch out'
ki.ka.ti
ma $=$ kikati-kałi
'to ask/to ask around'
b. an.qtu
ayqtu-qtu
'to complete/think about'
$\mathrm{m}=$ ar.faz
$\mathrm{m}=$ arfa-rfa- $z$
'to fly/to keep flying around'
in.kmir
ijkmi-kmi-r
'to roll into a ball/be rolled into a ball'
dut.khun
mia=dutkhu-khu-n
'hunched over/hunch over'

The reduplicant acts as a suffix in vowel-final words. For consonant-final words, it behaves as an infix, breaking up the final consonant and other segments of the root. Concerning the invariant shape of reduplicants, it seems to alternate between one to two syllables. I argue that the position of the reduplicant can be predicted accurately through Alignment interactions, but the size cannot solely depend on Alignment constraints (with other phono-constraints). A Generalized Template constraint $\mathrm{Red}=\mathrm{Stem}$, though indirectly referring to the mapping between the morphological category Red and a phonological category, can properly account for invariant shape.

\section{The position of reduplicants}

In pre-OT theories, Prosodic Circumscription (McCarthy and Prince 1990, 1995) dealt with the position of the infixing reduplicant by circumscribing a part and applying reduplication processes to either kernel or residue. However, sometimes the cut portion could not be incorporated into the Prosodic Hierarchy, such as with the 'onsetless syllable' in Timugon Murut (5). Within the theory of Generalized Alignment in OT, McCarthy and Prince propose an analysis manifesting the higher-ranking phono-constraint ONSET. With ONSET outranking LEFTMOST-RED, the reduplication skips over the onsetless syllable in order to improve the overall prosodic structure (om-po-podon rather than *om-ompodon). 
(5) Timugon Murut (Prentice 1971; cited in MaCarthey and Prince 1993)
a. limo
$\underline{\text { li-limo }}$
bulud
bu-bulud
'five/about five'
b. abalan
a-ba-balan
'hill/ridges in which tuberous crops are planted'
ompodon
om-po-podon
'bathes/often bathes'
'flatter/always flatter'

However, in Amis and other Formosan languages, a top-ranked NoCODA constraint would not improve the whole structure. Following previous work (McCarthy and Prince 1994, 1995, Gafos 1998, Downing 1998, 2000, Hendricks 2001, Crowhurst 2004), I argue that the position of the reduplicant can be predicted accurately through interactions of Alignment constraints which show morphology-prosody relations.

\subsection{An alignment analysis in Amis}

As shown in (1), Amis content words (which may undergo reduplication) end in consonants. Therefore, interactions between ROOT-Alignment and REDAlignment may accurately predict the positions of reduplicants. We adopt the templatic constraint at present and take the assumption that codas are moraic except when word-final. In Amis, the dominant templatic constraint RED=Stem only requires a size of two morae (i.e., a Foot) but not edge alignment. Ranking Align-Rt-R over RIGHTMOST could exclude the root-final consonant from reduplication. Interactions of constraints are illustrated in tableaux (7) and (8).

(6) Constraint definitions

\begin{tabular}{|lll|}
\hline a. & Align-Rt-R(ight): & $\begin{array}{l}\text { Align(Root, R, PrWd, R). Every root must coincide } \\
\text { with a prosodic word at the right edge. }\end{array}$ \\
\hline b. & RIGHTMOST: & $\begin{array}{l}\text { A reduplicant must align with the right edge of a } \\
\text { prosodic word. }\end{array}$ \\
\hline c. & Red=Stem: & Red equals a Stem, which is bimoraic. \\
\hline d. & MaxBR: & Every segment of B has a correspondent in R. \\
\hline
\end{tabular}

(7) Reduplication for Amis roots without medial clusters

\begin{tabular}{|c|c|c|c|c|}
\hline Input: /kałafu?, Red/ & Align-Rt-R & Red $=$ Stem & RIGHTMOST & MaxBR \\
\hline a. ka.ła.fu.-1a.fu-? & & & $*$ & $* *$ \\
\hline b. ka.ła.fu-ka.ła.fu-? & & *! & * & \\
\hline ka.ła.fu?-fu? & $* !$ & $*$ & & $* * * *$ \\
\hline d. ka.ła.-fur-fu? & & & $* *$ !* & \\
\hline
\end{tabular}


(8) Reduplication for Amis roots with medial clusters

\begin{tabular}{|c|c|c|c|c|}
\hline Input: /tamław, Red/ & Align-Rt-R & Red $=$ Stem & RIGHTMOST & MaxBR \\
\hline a. tam.1a-m.ła-w & & & $*$ & $* *$ \\
\hline b. tam.ła-tam.1a-w & & $* !$ & * & \\
\hline c. $\quad$ tam.-1aw-taw & & & $* ! * *$ & \\
\hline d. tam.ław. 1aw & $* !$ & * & & $* * *$ \\
\hline
\end{tabular}

In tableau (7), candidate (c) satisfies the RIGHTMOST constraint at the expense of violating dominant Align-RT-R. It also violates the size requirement of the reduplicant because of the non-moraic final consonant. Candidate (b) copies too much, violating the templatic constraint. In tableau (8), a full-copied candidate (b) violates the size restriction. Candidate (c) satisfies MaxBR but incurs more violations of RightMOST. Notice that in tableau (8), the existence of an undominated NOCODA constraint would not aid in selecting the optimal candidate.

\subsection{Mora alignment in some Formosan languages}

Since content words end in a consonant in Amis, the positions of infixing reduplicants can be attributed to the crucial ranking of Align-Rt-R $>>$ Align-RedR. However, in Pazih, Paiwan and Thao, the reduplicants behave as infixes in consonant-final roots but as suffixes in vowel-final ones. The ranking in Amis would be problematic for these cases. Consider the reduplicated forms in consonant-final and vowel-final roots. One thing consistent is that the reduplicants align the right edge on the mora tier. Adopting Crowhurst's (2004) mora alignment constraint, the positions of reduplicants can easily be accounted for. Analogous to constraint (6a) Align-Rt-R, a set of alignment constraint referring to different units (segments and morae) is incorporated into the analysis. For Align$\mathrm{Red}_{u}-\mathrm{R}$ to outrank Align- $\mathrm{Rt}_{u}-\mathrm{R}$, the reduplicant would press close to the right edge. Ranking Align-Rt $t_{s g}-R$ over Align-Red ${ }_{s g}-R$ ensures that the root stays at the right edge if possible. Moreover, for Align- $\mathrm{Red}_{\mu}-\mathrm{R}$ to outrank Align- $\mathrm{Rt}_{\mathrm{sg}}-\mathrm{R}$, a reduplicative infix emerges if the rightmost segment is a non-moraic root segment. The constraint ranking is illustrated in tableaux (9-10). (For the sake of space-saving, the 'Align' is abbreviated to 'A'.)

(9) Thao reduplication for roots without clusters

\begin{tabular}{|c|c|c|c|c|c|c|}
\hline /kikałi+Red/ & Red $=$ Stem & $\mathrm{A}-\operatorname{Red}_{\mu}-\mathrm{R}$ & $A-R t_{s g}-R$ & $A-\operatorname{Red}_{\mathrm{sg}}-\mathrm{R}$ & $A-R t_{\mu}-R$ & MaxBR \\
\hline a. kikałi-kałi & & & $*$ & & $* *$ & $* *$ \\
\hline b. kikał-ikał-i & & $* !$ & & $*$ & & $*$ \\
\hline kika-kika-łi & & $* !$ & & $* *$ & & \\
\hline
\end{tabular}




\begin{tabular}{|c|c|c|c|c|c|c|}
\hline /quliušs+Red/ & Red $=$ Stem & A-Red ${ }_{\mu}-\mathrm{R}$ & $A-R t_{s g}-R$ & $A-\operatorname{Red}_{s g}-R$ & $\mathrm{~A}-\mathrm{Rt}_{\mu}-\mathrm{R}$ & MaxBR \\
\hline d. quliu-liu-šs & & & & $*$ & $* *$ & $* *$ \\
\hline e. quliuš-liušs & & & $* ! * * *$ & & $* *$ & $*$ \\
\hline f. quli-quli-uš & & $* !$ & & $* *$ & & \\
\hline quliu-u-ǔš & $* !$ & & & $*$ & $*$ & $* * * *$ \\
\hline
\end{tabular}

In the above tableau, candidates (b-c) and ( $\mathrm{f}$ ) violate the dominant constraint Align-Red $\mathrm{d}_{\mu}-\mathrm{R}$. Candidate (e) satisfies Align- $\mathrm{Rt}_{\mathrm{sg}}-\mathrm{R}$ at the expense of violating a higher-ranked constraint. After competing, (a) and (d) are optimal. Notice that if the templatic constraint did not exist, candidate $(\mathrm{g})$ would defeat $(\mathrm{d})$. Once Align$\mathrm{Rt}_{\mu}-\mathrm{R}$ and Align- $\mathrm{Rt}_{\mathrm{sg}}-\mathrm{R}$ are satisfied, other Alignment constraints would squeeze the reduplicant to the minimum.

(10) Thao reduplication for roots with clusters

\begin{tabular}{|c|c|c|c|c|c|c|}
\hline$/ \mathrm{m}=\operatorname{arfaz}+\mathrm{Red} /$ & Red $=$ Stem & $\mathrm{A}-\operatorname{Red}_{\mu}-\mathrm{R}$ & $A-R t_{s g}-R$ & $A-\operatorname{Red}_{\mathrm{sg}}-\mathrm{R}$ & $\mathrm{A}-\mathrm{Rt}_{\mu}-\mathrm{R}$ & MaxBR \\
\hline a. $\mathrm{m}=$ arfa-rfa- $z$ & & & & $*$ & $* *$ & $* *$ \\
\hline b. $\quad m=$ arfaz-faz & $* !$ & & $* * *$ & & $*$ & $* * *$ \\
\hline c. $\quad m=a r f a-f a-z$ & $* !$ & & & $*$ & $*$ & $* * *$ \\
\hline d. $\quad m=$ arfa-marfa- $z$ & $* !$ & & & $*$ & $* * *$ & \\
\hline
\end{tabular}

Tableau (10) illustrates reduplication for roots containing a medial cluster. Again, candidates (b-d) are ruled out by the dominant constraint. If we take candidate (a), (c) and (d) into consideration and suppose that Red=Stem is absent, candidate (a) would never win out because its violations are between candidates (c) and (d) in the lowest two constraints. So the templatic constraint indeed plays an important role.

Alignment constraints indicating different units or categories (root, segment or mora) can deal with the suffixal reduplication in vowel- and consonant-final roots in the aforementioned Formosan languages. The correct reduplicative position can rely on Alignment interactions; however, not the reduplicant size. The constraints restricting reduplicative shape will be discussed in section 3 . In the following, languages displaying mora-alignment at the opposite edge are presented.

\subsection{A typology of mora alignment constraints}

Reduplication in Pazih, Paiwan and Thao has shown the right-edge effects of mora alignment constraints. Mora alignment at the left edge is also attested. Infixing reduplication in Mangarayi (Merlan 1982, McCarthy and Prince 1986) is a case of mora-tier evaluation at the left edge. 
(11) Mangarayi partial reduplication

$\begin{array}{lll}\text { gamag } & \text { g-a.m-a.mag.-ji } & \text { 'digging stick/having digging sticks' } \\ \text { jim.gan } & \text { j-im.g-im.gan } & \text { 'knowledgeable one sg./pl.' } \\ \text { muyg-ji } & \text { m-uyg.j-uy.g-ji } & \text { 'having a dog/having a lot of dogs' }\end{array}$

Mangarayi reduplication is a mirror image of Amis and Thao, especially words containing medial clusters. Crowhurst (2004) proposes two crucial rankings, LEFTMOST-Rt $_{\text {SEG }}>>$ LEFTMOST-Red SEG $_{\text {and LEFTMOST-Red }}>>$ LEFTMOST-Rt ${ }_{\mu}$. The interactions predict not only the reduplicant position but also the size. Once $\mathrm{L}-\mathrm{Rt}_{\text {seg }}$ and L-Red ${ }_{\mu}$ are satisfied, the reduplicant would copy as much as possible. The copy should not exceed one mora or it would incur more violations of L-Red ${ }_{\mu}$.

To sum up, this section presents data which favors the alignment constraint evaluated on the mora tier. Moreover, interactions between mora and segment alignment constraints predict different language types.

\section{The invariant shape of reduplicants}

A property of reduplicants is their steadfast size. In pre-OT phonology, a morphological-specific-template was stipulated to control the size. In OT the concept was directly transferred into a templatic constraint in the form of 'Red=X', meaning that Red equals a certain unit X (McCarthy and Prince 1993). Later, the Generalized template restricted the size by AFFIX $\leq \sigma$ or STEM=PRWD, mapping prosodic categories to morphological categories (McCarthy and Prince 1994, 1995). Recently, it has been proposed and exemplified that templatic constraints can be decomposed into interactions of a set of Alignment constraints (Gafos 1998, Hendrick 2001, Chrowhurst 2004). Based on partial reduplication data in Amis and Thao, I argue that templatic constraints still cannot be eliminated.

To see how Alignment interactions substitute the function of a templatic constraint, partial reduplication in Semai (Hendrick 2001) and Mangarayi (Crowhurst 2004) is illustrated below. But we will show that in Amis and Thao the accurate reduplicated form is neither maximal nor minimal and cannot win out if solely depending on Alignment interactions.

Semai expressive reduplication (Diffloth 1976, Hendrick 2001) copies the initial and the final consonant as the reduplicant, as shown in (12).

(12) Semai expressive reduplication

\begin{tabular}{|c|c|c|}
\hline & th-taPoh & 'appearance of large stomach constantly bulging out' \\
\hline & $\underline{\text { SW-slaye:W }}$ & 'long hair in order' \\
\hline & kc-kmr? $\varepsilon^{\prime c}$ & 'short, fat arms' \\
\hline
\end{tabular}


The reduplicant copies one segment from each edge. The invariant shape of the reduplicant is difficult to account for by stipulating a template which is in the shape of a syllable without a nucleus. Ranking R-ANCHOR ${ }_{I R}$ and L-ANCHOR $I R$ undominated, Hendrick (2001) proposes the crucial ranking ALIGN-RED-L $>>$

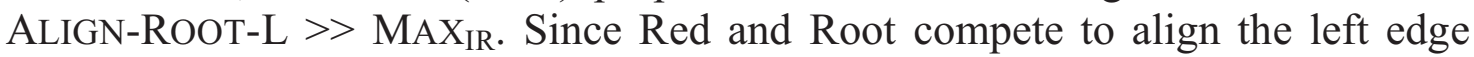
and ALIGN-RED-L is dominant, the reduplicant would sacrifice segment correspondence to incur fewer violations of ALIGN-ROOT-L. Thus the size of the reduplicant is compressed to a minimal $\mathrm{CC}$ constituent. The use of Alignment interactions is straightforward in Semai, as it is in Mangarayi. Crowhurst (2004) posits sets of Alignment constraints to deal with Mangarayi reduplication. For

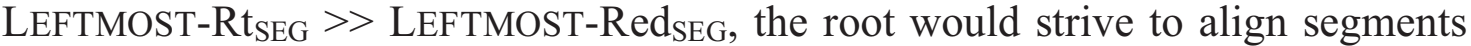
at the left edge; for LEFTMOST-Red ${ }_{\mu}>$ LEFTMOST-Rt $_{\mu}$, the mora alignment of the reduplicant is satisfied if there is no root mora preceding the reduplicant. Therefore, interactions of the ranking squeeze the reduplicant size in order to satisfy both LEFTMOST-Rt SEG $_{\text {and LEFTMOST-Red }}$. The minimal partial reduplication can insightfully be accounted for by Alignment interactions.

Partial reduplication in Amis and Thao has several properties that distinguish it from the minimal partial reduplication of Semai and Mangarayi. First, the reduplicant in Amis and Thao is neither minimal (smaller than a syllable) nor maximal (whole root or prosodic word). Second, the reduplicant sometimes misaligns both edges with certain prosodic units. For example, Amis has a bimoraic reduplicant. If we adopt the ranking for Mangarayi, the reduplicant would copy as minimally as possible when both top-ranking Alignment constraints are satisfied, as in (13). Thus the ranking selects the accurate choice (d) in words containing clusters but fails to choose the correct one (a) in opensyllable words. A win-win situation cannot be gotten even if $\mathrm{RMOST}^{-\mathrm{Rt}_{\mu}}$ and MAXBR are reranked.

(13) Alignment interactions in Amis

\begin{tabular}{|c|c|c|c|c|}
\hline /patsi?əy + Red/ & RMOST-Red $_{\mu}$ & RMOST-Rt SEG $_{\text {S }}$ & $\mathrm{RMOST}-\mathrm{Rt}_{\mu}$ & MAXBR \\
\hline 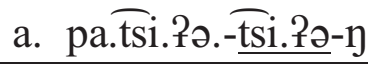 & & & $* *$ & pa \\
\hline b. :) pa.tsi.?ə-?ə-1 & & & & patsi \\
\hline \multicolumn{5}{|l|}{$/$ tamław + Red/ } \\
\hline c. tam.1a.-tam.1a-w & & & $* * *$ & \\
\hline d. ${ }^{-}$tam. $1 a-m .1 a-w$ & & & $* *$ & ta \\
\hline
\end{tabular}

Another possible solution can be turned to: an Alignment constraint mapping an augment to a certain phonological category. An augment is defined as 'the size increment by which the reduplicated form is extended compared to the corresponding unreduplicated form' (Crowhurst 2004:131). The augment-Red alignment constraint, such as 'RED- $\sigma_{\mu \mu}$ LEFT $_{\mathrm{SEG}}$ ' (Align(Red, L, $\left.\sigma_{\mu \mu}, \mathrm{L}\right)$ ), has 
been used in dealing with partial reduplication in Hopi (Hendrick 1999), Mokilese and Kamaiurá (Crowhurst 2004). The benefit of such a constraint is to demand an edge correspondence between the reduplicant and some phonological category without counting the size of the reduplicant. For example, Kamaiurá reduplication (Everett and Seki 1985, McCarthy and Prince 1986) in (14) mirrors two syllables from the right without the final consonant, just as in the case of Paiwan and Pazih. The ranking RED-PRWD- $\mathrm{L}_{\mu}$, RMOST-RED $\mathrm{R}_{\mu} \gg \mathrm{RMOST}^{-\mathrm{RT}_{\mu}} \gg>$ MAXBR cleverly predicts the disyllabic forms.

(14) Kamaiurá partial reduplication
a. o.hu.ka
o.hu.ka.-hu.ka
'he laughed'
b. a.pot
a.po.-a.po-t
'I jump'
c. o.mo.tu.muy
o.mo.tu.mu.-tu.mu-n
'he shook it'

Analogously, we could posit a constraint that demands the reduplicant must align with the left edge of a bimoraic foot. The first problem with this is footparsing. Amis has only primary stress, which falls on the last syllable. How could a reduplicant align with a foot in a suffixed form like lu.p.a-lu.(pa. $-s=a ́ n)$ ? If we restrict Red-Ft alignment to within the root, open-syllable words would be fine:

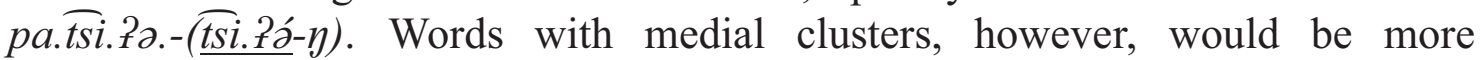
problematic. Should we postulate a foot spanning over syllable boundaries, like tam.ta-(m.ta)-w? It is not solved yet and needs further investigation. Hence I conservatively argue that a templatic constraint cannot be eliminated at present.

\section{Conclusion and implications}

This paper examined the functions of Alignment constraints in reduplication, especially in accounting for the position and the size of reduplicants. Examples from several Formosan languages argue for the use of mora alignment constraints, which evaluate violations on the mora tier. Patterns on both edges exist, certifying such a constraint. As for shape invariance, the case of Amis and Thao may not appeal to Alignment interactions only. They are unable to compress partial reduplication which is not a minimal copy. Therefore, I argue for the need of a templatic constraint at the present stage, but how to reduce such stipulation into interactions of primitive constraints requires further research.

\section{References}

Blust, Robert. 2003. Thao Dictionary. Taipei: Academia Sinica.

Chang, Hsiu-chuan. 2000. Paiwanyu tsankao yufa. Taipei: Yuanliu Press.

Chang, M. Laura. 1998. Thao reduplication. Oceanic Linguistics 37(2): 277-297. 
Crowhurst, Megan. 2004. Mora Alignment. Natural Language \& Linguistic Theory 22: 127-177.

Diffloth, G. 1976. Expressives in Semai. In P. Jenner et al. (eds.) Austroasiatic Studies. Honolulu: The University of Hawaii Press.

Downing, Laura. 1998. On the prosodic misalignment of onsetless syllables. Natural Language \& Linguistic Theory 16: 1-52.

Everett, Daniel, and Lucy Seki. 1985. Reduplication and CV skeleta in Kamaiurá. Linguistic Inquiry 16: 326-330.

Gafos, Diamandis. 1998. A-templatic reduplication. Linguistic Inquiry 29(3): 515527.

Hendrick, Sean. 1999. Reduplication without template constraints: A study in bare-consonant reduplication. PhD diss., University of Arizona, Tucson.

Hendrick, Sean. 2001. Bare-consonant reduplication without prosodic templates: Expressive reduplication in Semai. Journal of East Asian Linguistics 10: 187306.

Li, Paul Jen-kuei, and Shigeru Tsuchida. 2001. Pazih Dictionary. Taipei: Academia Sinica.

McCarthy, John, and Alan Prince. 1986. Prosodic Morphology. Ms., University of Massachusetts, Amherst and Brandeis University, Waltham, Mass.

McCarthy, John, and Alan Prince. 1990. Foot and word in prosodic morphology: The Arabic broken plural. NLLT 8, 209-283.

McCarthy, John, and Alan Prince. 1993. Generalized Alignment, in G. E. Booij and J. van Marle (eds.) Yearbook of Morphology 1993, 79-153. Dordrecht: Kluwer.

McCarthy, John, and Alan Prince. 1994. Two lectures on prosodic morphology. Handouts of two lectures at OTS/HIL Workshop on Prosodic Morphology, Utrecht University, July 1994. [ROA-59, http://ruccs.rutgers.edu/roa.html]

McCarthy, John, and Alan Prince. 1995. Faithfulness and reduplicative identity, in J. Beckman, S. Urbanczyk, and L. Walsh (eds.) University of Massachusetts Occasional Papers in Linguistics 18, 249-384. Amherst, MA: Graduate Linguistic Student Association.

Merlan, Francesca. 1982. Mangarayi, Lingua Descriptive Series 4. Amsterdam: North Holland.

Prentice, D. J. 1971. The Murut language of Sabah. Pacific Linguistics 18. Canberra: Australian National University.

Tseng, Meylysa. 2002. Paiwan reduplication: meaning and structure. Proceedings of 2002 National Conference on Linguistics. Jiayi: Chung Chen University.

Graduate Institute of Linguistics

National Tsing Hua University

101 Kuang Fu 2nd Road

Hsingchu, Taiwan 300

d928704@oz.nthu.edu.tw 